\title{
Self measured home blood pressure was better than "clinic blood pressure for predicting stroke in a Japanese population
}

Asayama K, Ohkubo T, Kikuya M, et al. Prediction of stroke by self-measurement of blood pressure at home versus casual screening blood pressure measurement in relation to the Joint National Committee 7 classification: the Ohasama study. Stroke 2004;35:2356-61.

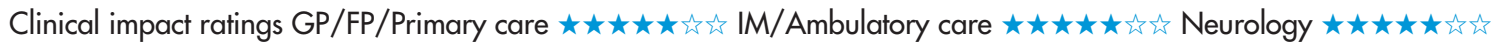

In a Japanese population, is self measured home blood pressure (BP) or clinic BP measured by healthcare professionals accurate for predicting the risk of a stroke or transient ischaemic attack (TIA)?

\section{METHODS}

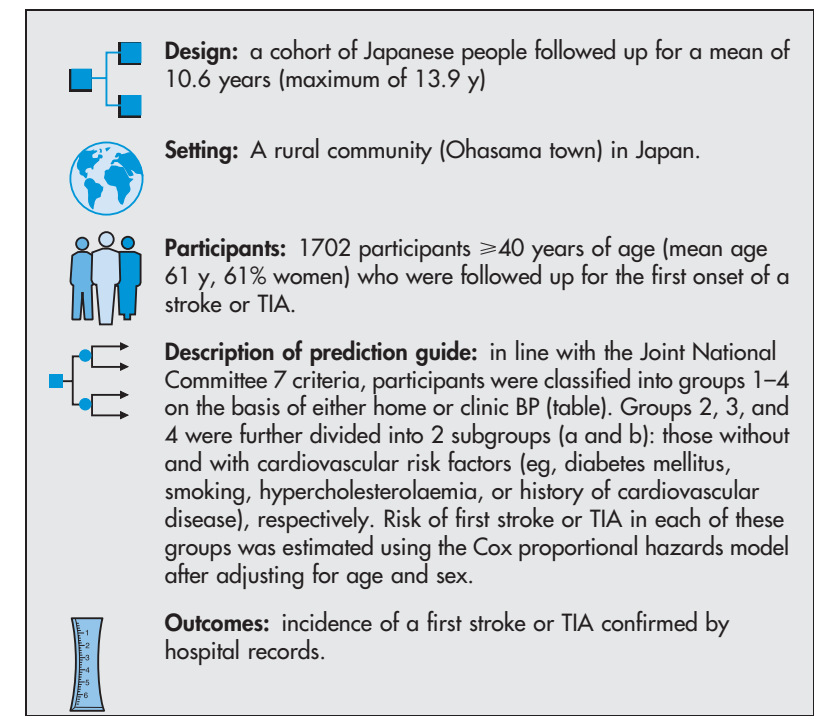

MAIN RESULTS

$8.3 \%$ of participants had a stroke or TIA. The table shows hazard ratios for groups $2-4$ compared with group 1 .

For correspondence: $\mathrm{Dr} \mathrm{Y}$ Imai, Tohoku University Graduate School of Pharmaceutical Science and Medicine, Sendai, Japan. rinsyo@bureau.tohoku. ac.jp

Source of funding: not stated

\section{CONCLUSION}

In a Japanese population, self measured home blood pressure was more consistent than "clinic" blood pressure for predicting the risk of stroke or transient ischeamic attacks.

Commentary

M any studies have confirmed that home $\mathrm{BP}$ readings are generally 8-12 $\mathrm{mm} \mathrm{Hg}$ lower for systolic and $4-6 \mathrm{~mm} \mathrm{Hg}$ lower for diastolic compared with office readings. Ambulatory BP monitoring (ABPM) further showed an association between the common occurrence of white coat hypertension and an intermediate cardiovascular risk relative to patients with normal $B P$ and those with sustained elevations. Both home BP and ABPM provide more data by which to judge BP control than episodic clinic visits. ${ }^{1}$ Home BP determinations carry some cautions for implementation and interpretation. ${ }^{2}{ }^{3}$ Morning readings offer useful correlates to circadian variation in risk factors (ie, high cortisol, high sympathetic tone, hypercoagulability, hypofibrinolysis, and drug concentration nadirs). ${ }^{4}$ Other patient behaviour, like squatting or eating, may respectively raise or lower $\mathrm{BP}$, predisposing to $\mathrm{BP}$ instability and stroke. ${ }^{5}$ The study by Asayama et al builds on previous data $^{6}$ confirming the enhanced value of home BP as a predictor of target organ damage compared with office BP readings.

Peter Rudd, MD Stanford University Stanford, California, USA

1 Jain A, Krakoff LR. Blood Press Monit 2002;7:157-61.

2 Gerin W, Schwartz AR, Schwartz JE, et al. Blood Press Monit 2002;7:313-8.

3 Imai $Y$, Otsuka K, Kawano Y, et al. Hypertens Res 2003;26:771-82.

4 Shimada K, Kario K, Umeda Y, et al.Blood Press Monit 2001;6:349-53.

5 Hossain M, Ooi WL, Lipsitz LA. J Clin Epidemiol 2001;54:488-94.

6 Sakuma M, Imai Y, Tsuji I, et al. Hypertens Res 1997;20:167-74.

Self measured home blood pressure (HBP) v "clinic" blood pressure (CBP) measured by healthcare professionals for predicting the risk of stroke at a mean follow up of 10.6 years*

\begin{tabular}{|c|c|c|c|c|c|c|c|}
\hline $\begin{array}{l}\text { Type } \\
\text { of BP }\end{array}$ & Category definitions & $\begin{array}{l}\text { Systolic BP } \\
\mathrm{mm} \mathrm{Hg}\end{array}$ & & $\begin{array}{l}\text { Diastolic BP } \\
\mathrm{mm} \mathrm{Hg}\end{array}$ & $\begin{array}{l}\text { CVD risk } \\
\text { factors }\end{array}$ & Group & Hazard ratio $(95 \% \mathrm{Cl})$ \\
\hline \multirow[t]{7}{*}{$\mathrm{HBP}$} & Normotension & \multirow{3}{*}{$\begin{array}{r}<115 \\
115-134\end{array}$} & And & \multirow{3}{*}{$\begin{array}{r}<75 \\
75-84\end{array}$} & Yes or no & 1 & $1.0+$ \\
\hline & \multirow[t]{2}{*}{ Prehypertension } & & \multirow[t]{2}{*}{ Or } & & No & $2 a$ & $1.9(0.9$ to 4.1$) \neq$ \\
\hline & & & & & Yes & $2 b$ & $2.6(1.2$ to 5.5$) \ddagger$ \\
\hline & \multirow[t]{2}{*}{ Stage 1 hypertension } & \multirow[t]{2}{*}{$135-149$} & \multirow[t]{2}{*}{ Or } & \multirow[t]{2}{*}{$85-94$} & No & $3 a$ & $2.4(1.1$ to 5.3$)$ \\
\hline & & & & & Yes & $3 b$ & 6.7 (3.2 to 14.3$) \pm$ \\
\hline & \multirow[t]{2}{*}{ Stage 2 hypertension } & \multirow[t]{2}{*}{$\geqslant 150$} & \multirow[t]{2}{*}{ Or } & \multirow[t]{2}{*}{$\geqslant 95$} & No & $4 a$ & $2.9(1.1$ to 7.6$)$ \\
\hline & & & & & Yes & $4 b$ & 6.4 (2.8 to 14.6$)$ \\
\hline \multirow[t]{7}{*}{ CBP } & Normotension & \multirow{3}{*}{$120-139$} & And & \multirow{3}{*}{$\begin{array}{r}<80 \\
80-89\end{array}$} & Yes or no & 1 & $1.0 \dagger$ \\
\hline & \multirow{2}{*}{ Prehypertension } & & \multirow{2}{*}{ Or } & & No & $2 a$ & $0.9(0.5$ to 1.8$)$ \\
\hline & & & & & Yes & $2 b$ & $1.7(0.9$ to 3.0$) \neq$ \\
\hline & \multirow[t]{2}{*}{ Stage 1 hypertension } & \multirow[t]{2}{*}{$140-159$} & \multirow[t]{2}{*}{ Or } & \multirow[t]{2}{*}{$90-99$} & No & $3 a$ & $0.7(0.3$ to 1.6$)$ \\
\hline & & & & & Yes & $3 b$ & $2.6(1.4$ to 4.9$) \ddagger$ \\
\hline & \multirow[t]{2}{*}{ Stage 2 hypertension } & \multirow[t]{2}{*}{$\geqslant 160$} & \multirow[t]{2}{*}{ Or } & \multirow[t]{2}{*}{$\geqslant 100$} & No & $4 a$ & 2.1 (1.0 to 4.2 ) \\
\hline & & & & & Yes & $4 b$ & $2.9(1.3$ to 6.6$)$ \\
\hline
\end{tabular}

*BP = blood pressure; $\mathrm{CVD}=$ cardiovascular disease; CVD risk factors included diabetes mellitus, hypercholesterolaemia, smoking, and history of CVD. $\mathrm{Cl}$ defined in glossary.

fUsed as baseline for the respective type of BP.

‡lazard ratios provided by author. 